\title{
Comparison of Resilience, Self-Differentiation, and Health-Promoting Lifestyle in Children of the Chemical Warfare Veterans, Non- Chemical Veterans, Prisoners of War and Normal Population
}

\section{ART I C L E INF O}

\section{Article Type}

Descriptive Study

\section{Authors}

Ghasemiyani B. ${ }^{* 1} M A$,

Aghdasi A.N. ${ }^{2} P h D$

How to cite this article
Ghasemiyani B, Aghdasi A.N.
Comparison of Resilience, Self-
Differentiation, and Health-Prom-
oting Lifestyle in Children of the
Chemical Warfare Veterans, Non-
Chemical Veterans, Prisoners of
War and Normal Population. Iran-
ian Journal of War \& Public Health.
$2019 ; 11(4): 215-222$.

${ }^{1}$ Clinical Psychology Department, Humanities Faculty, Tabriz Branch, Islamic Azad University, Tabriz, Iran ${ }^{2}$ Psychology Department, Humanities Faculty, Tabriz Branch, Islamic Azad University, Tabriz, Iran

\section{*Correspondence}

Address: Tabriz Branch, Islamic Azad University, Pasdaran Highway, Tabriz, Iran. Postal Code: 5157944533 Phone: +98 (44) 44324450

Fax: -

hesel6370@gmail.com

\section{Article History}

Received: January 16, 2019

Accepted: September 4, 2019

ePublished: December 21, 2019

\section{A B S T R A C T}

Aims War-related physical and psychological injuries are the factors that affect the quality of life of disabled veterans and their children. The aim of the present research was to compare the resilience, self-differentiation, and health-promoting lifestyle in children of chemical warfare veterans, non-chemical warfare veterans, prisoners of war, and normal population. Instruments \& Methods This descriptive causal-comparative study was carried out on 259 children of the chemical warfare veterans, non-chemical warfare veterans, prisoners of war and normal population in Sardasht County in 2017-2018. The subjects were selected using purposive sampling method. Data collection tools consisted of the Conver and Davidson's resiliency questionnaire, self-differentiation questionnaire of Friedland and Skowron, and health improvement lifestyle questionnaire of Volker et al. Data were analyzed through SPSS 23 software using the one-way analysis of variance, Tukey post hoc and multivariate analysis of variance test.

Findings The mean scores of resiliency, self-differentiation and health-promoting lifestyle were significantly different among the four groups and this difference was observed between the children of normal population with the children of the chemical warfare veterans, nonchemical warfare veterans and prisoners of war $(\mathrm{p}<0.05)$ and there was no significant difference between the other groups ( $\mathrm{p}>0.05)$.

Conclusion The rate of resilience, self-differentiation, and health-promoting lifestyle in the children of normal population is higher than the other groups.

Keywords Resilience; Self-Differentiation; Health Promotion; Lifestyle

\section{I T A T I O N L I N K S}

[1] Mental health in group of war veterans and their spouses ... [2] Teacher and family career ... [3] Investigating and comparing the family function ... [4] Ordinary majic: resilience processes ... [5] Development of a new resilience scale: the ... [6] Relationship between spiritual intelligence ... [7] Resilience and vulnerability to adverse developmental ... [8] Academic buoyancy: towards an understanding ... [9] Ego-control and ego-resiliency: Generalization ... [10] Comparison of differentiation of self and cognitive ... [11] The relationship between differentiation of self ... [12] Family therapy in clinical ... [13] Family ... [14] A construc validiyy of differentiation of self ... [15] Mediating and moderating effects of differentiation ... [16] Comparing self-differentiation and psychological ... [17] How social connectedness affects guilt and ... [18] Differentiation of self mediates college stress ... [19] Differentiation of self and psychological ... [20] Forgiveness, spiritual instability, mental ... [21] Predicting health promoting lifestyle from health locus ... [22] Reliability and validity of Persian version of the ... [23] Construction and validation of the lifestyle ... [24] Health promotion in nursing ... [25] Cosmopolitan art and cultural... [26] Lifestyle interventions to prevent osteoporotic fractures ... [27] Comparison of health promotion and happiness ... [28] Health promoting lifestyle and its related ... [29] Investigating the relationship between differentiation ... [30] Comparison of health promoting lifestyle in HIV-positive ... [31] Social status of Martyrs' Spouses ... [32] comparative study of the mental health of war ... [33] Resilience, mental health and life ... [34] Comparison of resiliency in parents of children ... [35] The relationship between resilience and life ... [36] Differention of self inventoty short form: creation ... [37] Psychometric measures of family scale ... [38] Family therapy: an ... [39] Promoting healthy behaviors: how ... [40] Refugees' perceptions of healthy ... [41] Health promoting lifestyles and self-efficacy in ... 
مقايسه شود. روشن است هركاه جامعهاي از خانوادههاى متعادل و

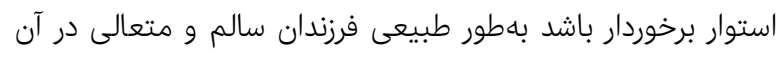

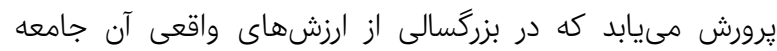

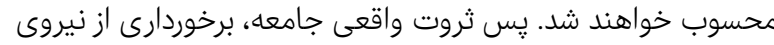

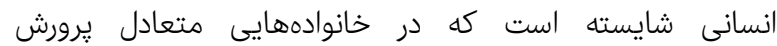

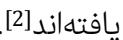

يكى از عوامل آسيبرسان به ساختار خانواده، معلوليت يكى از

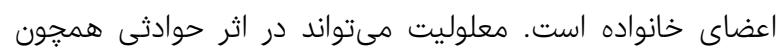

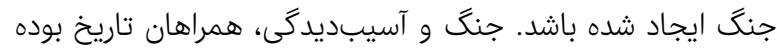

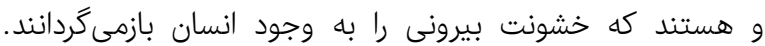

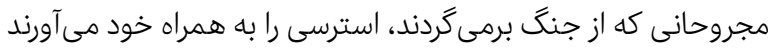

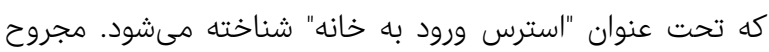
جنكى ممكن است عضو فعال، ارشد و دلسوز خانواده يعنى يدر باش باشد

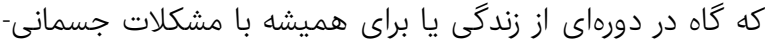

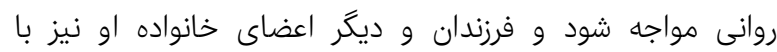
تاثيريذيرى از اين مساله، دجار مشكلاتى شوند. فرد جانباز بهواسطه

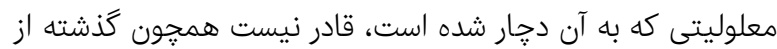

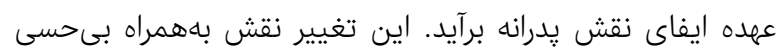

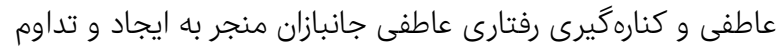

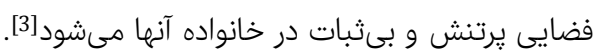

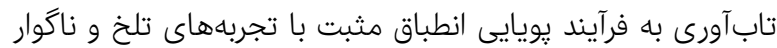

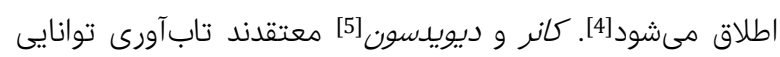
فرد در برقرارى تعادل زيستى روانى در شرايط خطرناك است. الفران افراد

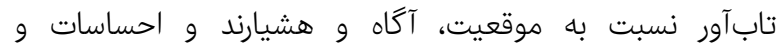

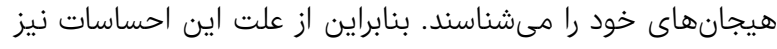

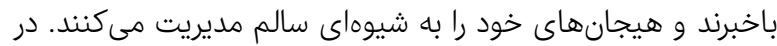

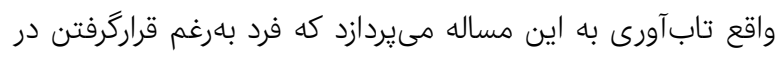

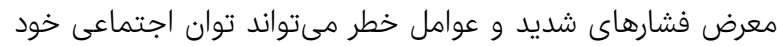

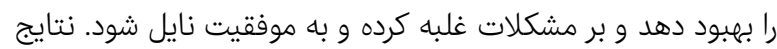

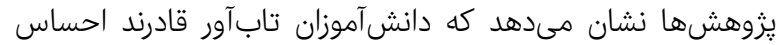

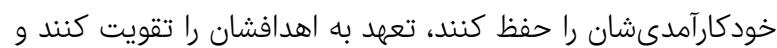

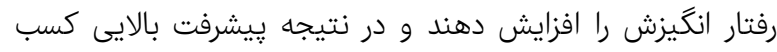

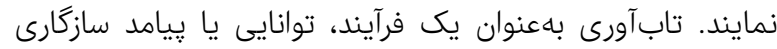

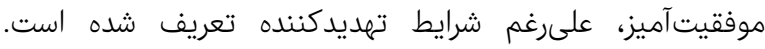

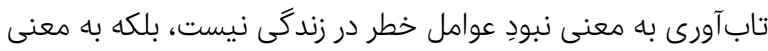

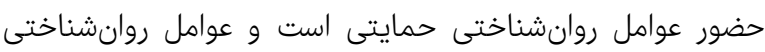
حمايتى در افراد مىتوانند به فرآيندها و روشائهاى استى عملكردى اطلاق

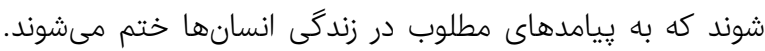

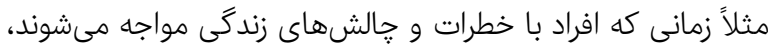

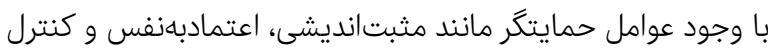

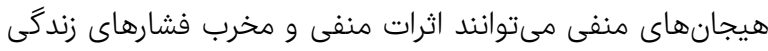

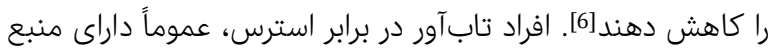

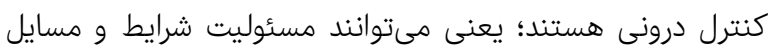
خود را بر عهده گيرند، خودشناسى مثبت دارند و نسبت بندئ به زندكى

\section{مقايسه ميزان تابآورى، تمايزيافتكى خود و سبك زندگى ارتقادهنده سلامت بين فرزندان جانبازان شيميايى، جانبازان غيرشيميايى، آزاده و افراد

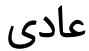

MA " بيانه قاسميانى

كروه روانشناسى بالينى، دانشكده علوم انسانى، واحد تبريز، دانشكاه آزاد اسلامى، تبريز، ايران

علىنقى اقدسى PhD كَروه روانشناسى، دانشى دانده علوم انسانى، واحد تبريز، دانشكاه آزاد اسلامى، تبريز، ايران

جكيده اهداف: آسيبهاى جسمى و روانى ناشى از جنگ، از جمله عواملى است كه

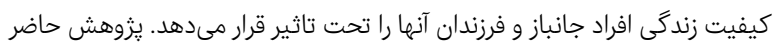

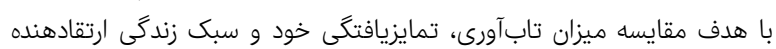

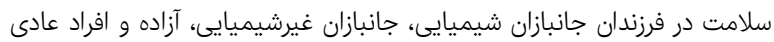

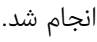

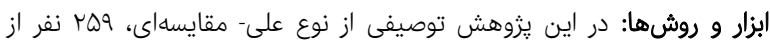

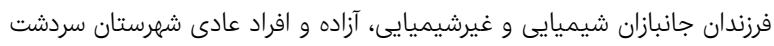

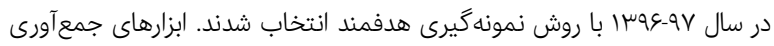

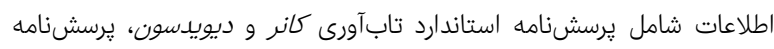

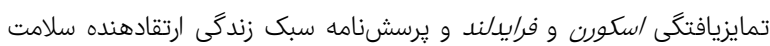

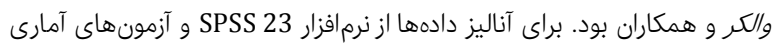

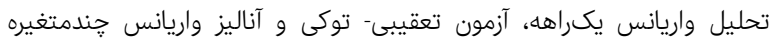
استفاده شد.

يافتهها: ميانگين نمرات تابآورى، تمايزيافتخى خود و سبك زندگى ارتقادهنده

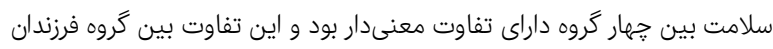

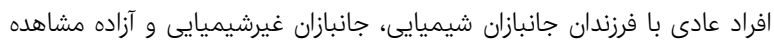

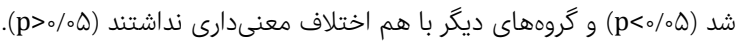

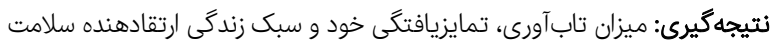

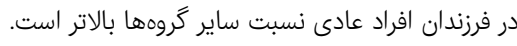

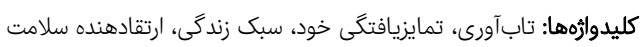

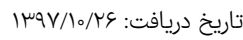

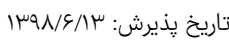

'نويسنده مسئول: hesel6370@gmail.com

مقدمه

جنَ هشتساله عراق عليه ايران لطمه و خسارات همهانانبهاى به

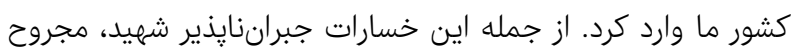

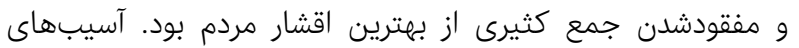

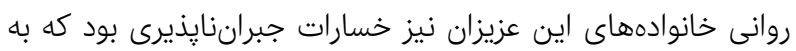

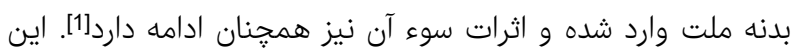

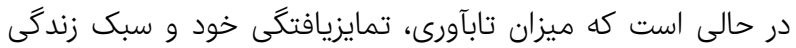

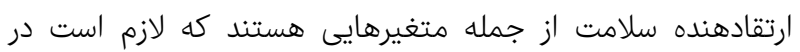

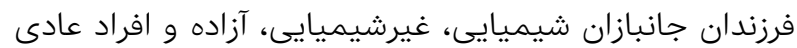




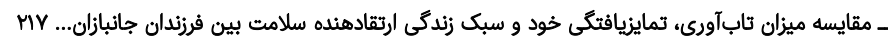

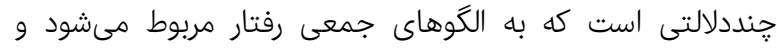
خوشبين هستند[7]. اين افراد داراى شخصيتهاى قوى هستند و

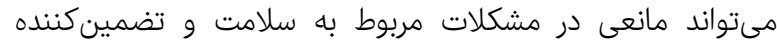

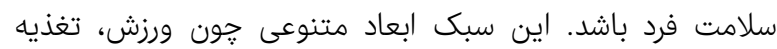

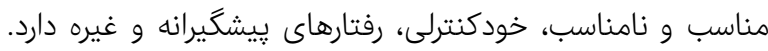
جوهره تعريف سبك زندگي سلامتمحور، انسجام در انجامدادن

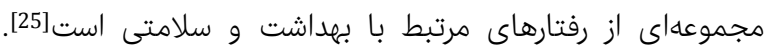

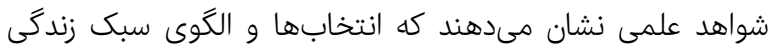

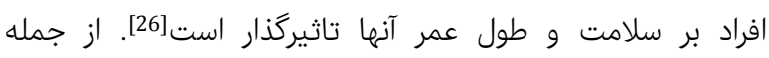

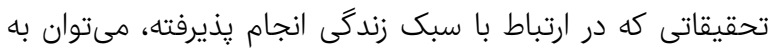

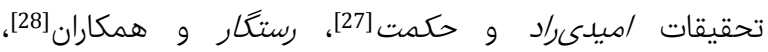
كيخسروى[29] و /بر/هيمبابايى و همكاداران [30] اشاره كرد. در اين ارتباط /براهيمبابايى و همكاران [30] در تحقيقى با عنوان مقايسه

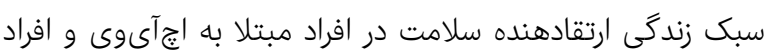

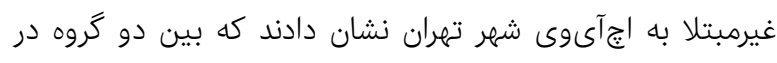
متغير سبك زندگى تفاوت وجود دارد.

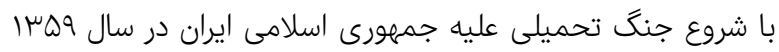

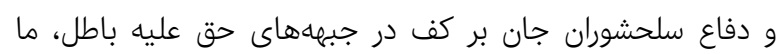

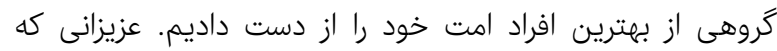

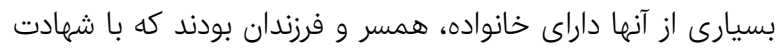
و قطع عضو آنها مشكلات فراوانى در زندگى خانوادههاى آنان ايجاد

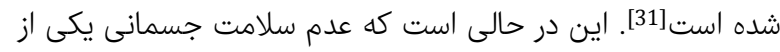

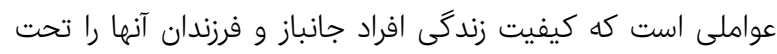

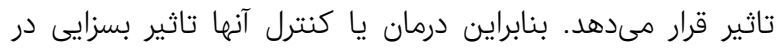

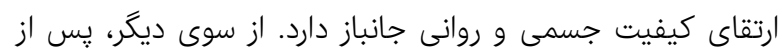

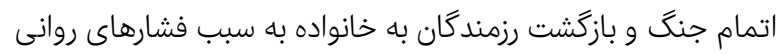
ناشى از جنگ و اثر تخريبى آن بر وضعيت روانى افراد، تاثير

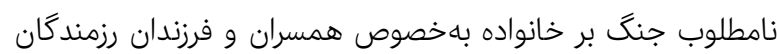

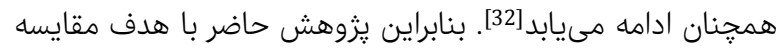

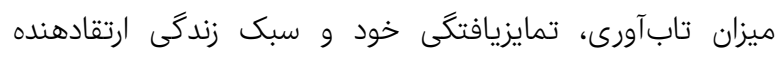

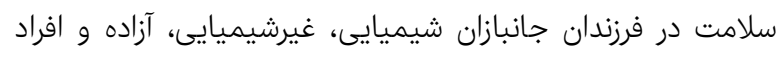

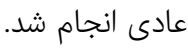

\section{ابزار و روشها}

يزّوهش توصيفى حاضر از نوع على- مقايسهاى است. جامعه آمارى روس

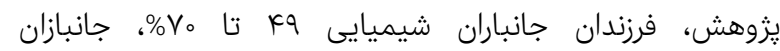

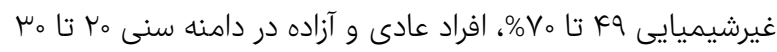

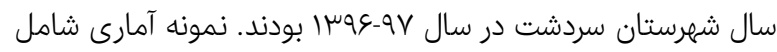

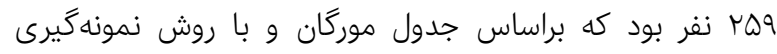

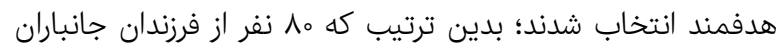

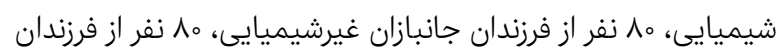

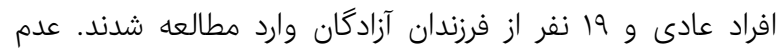
تناسب بين حجم نمونههاى هر گروه مربوط به آمار استان در

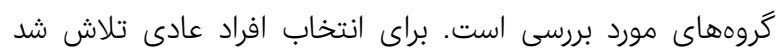

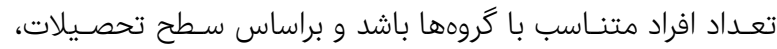

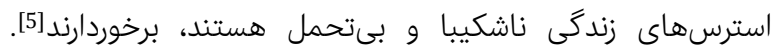

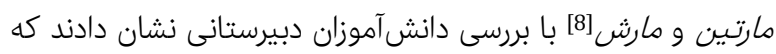

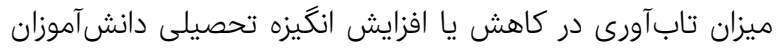

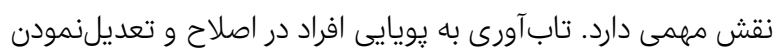

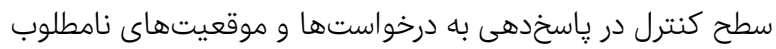
و ييشآمدهاى منفى اشاره دارد[9].

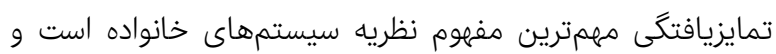

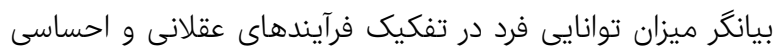

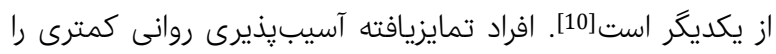

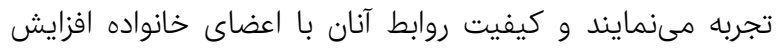
خواهد يافت و نقش مهمى بر تجربه اعضاى خانواده از تنش خواهن

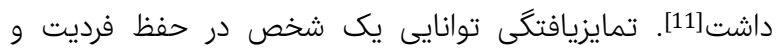

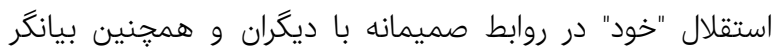

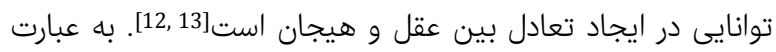

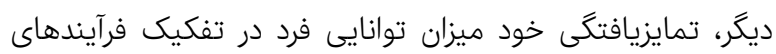

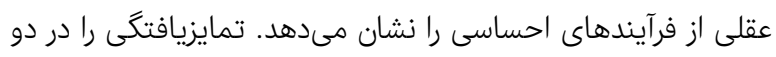

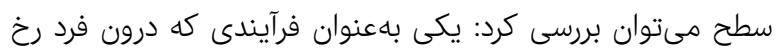

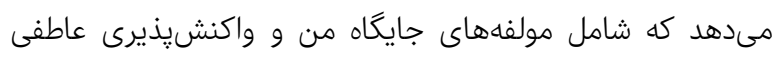

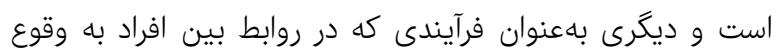

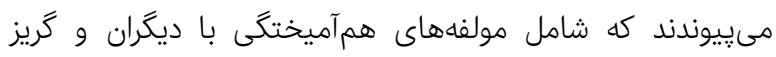
عاطفى است[14]. شواهد تجربى بهطور گسترده از تاثير سطح تمايز

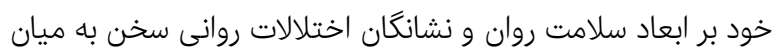

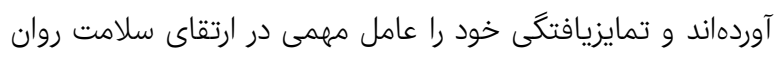

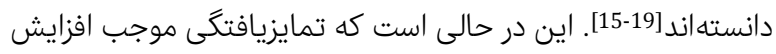

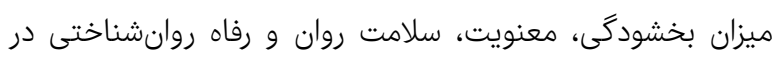
افراد مىشود [20]. سبك زندگى ارتقادهنده سلامت، يكى از معيارهاى تعيينكنيده

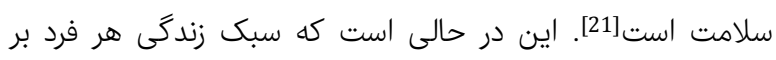
سلامت او تاثير دارد و فعاليتهاى ارتقادهنده سلامت ور شالى شيوه زندگى بهداشتى، استراتزىهاى اصلى تسهيل و حفاظت از سلامتى

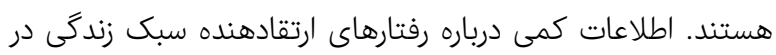

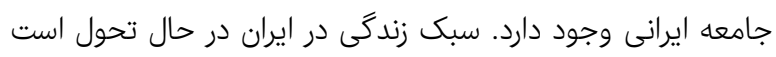

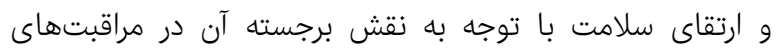

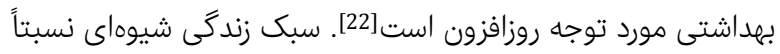

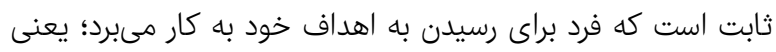

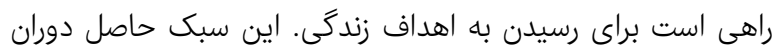

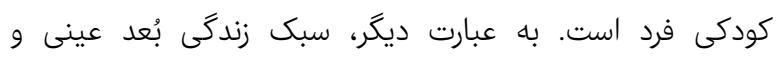

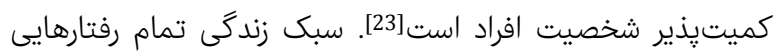

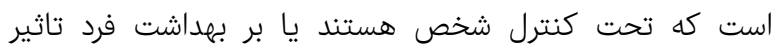

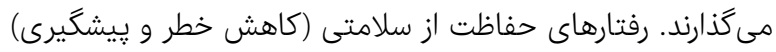

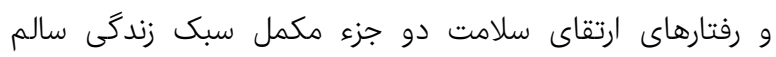

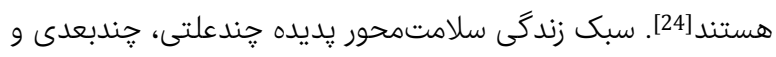




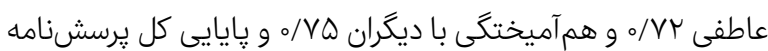

ه محاسبه شد ماس

بر- برسشنامه سبك زندگى ارتقادهنده سلامت والكر و همكاران:

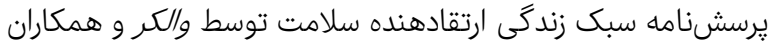

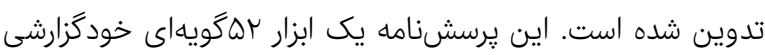
است كه سبك زندگى سلامتمحور را با تمركز بر كارهاى ابتكارى و و

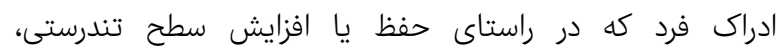

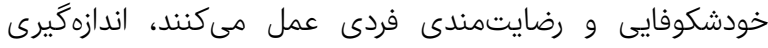

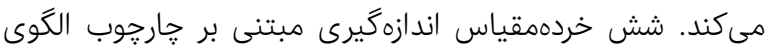

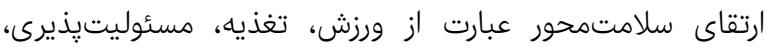
مديريت استرس، حمايت بينفردى و خودشكوفايى هستند. پإيايى إيى اين يرسشنامه در يك مطالعه در ايران (يزد) در تمام زيرمقياسهانيا

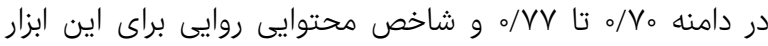

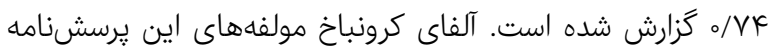

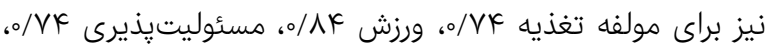

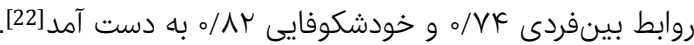
دادهها توسط نرمافزار SPSS 23 مورد آناليز قرار كرفت. بكامنظور

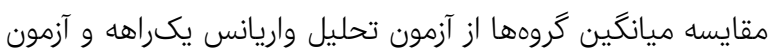

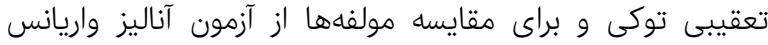

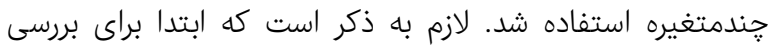

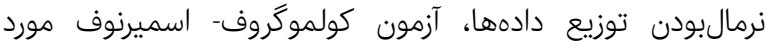

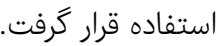

\section{يافتهها}

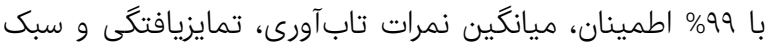

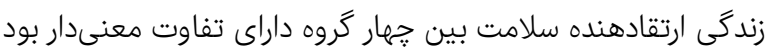

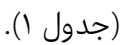

طبقه اجتماعى و سن همكن شوند. بدين منظور تعداد مي نفر بهصورت هدفمند در سطح شهر انتخاب شدند. نحوه انتخاب فرزندان

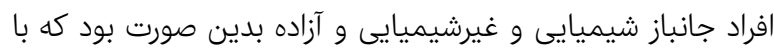

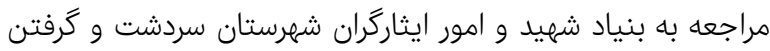

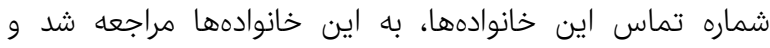

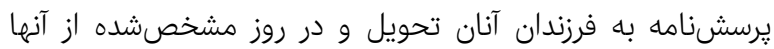
تحويل كرفته شد.

ابزار كردآورى اطلاعات شامل برسش نافنامههاى زير بود:

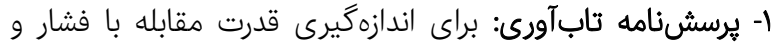

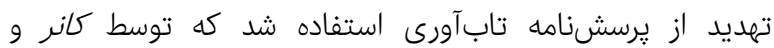

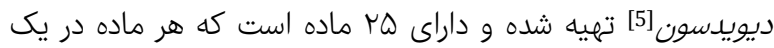

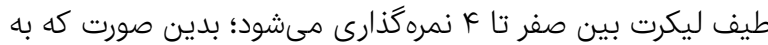

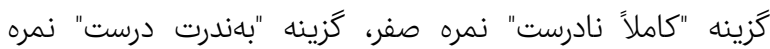

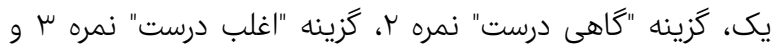

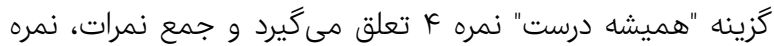
كل مقياس را تشكيل مىدهد. كمترين نمره و بيشترين نمره

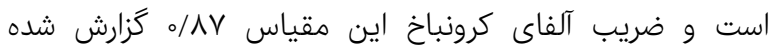

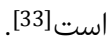
r- برسشنامه تمايزيافتكى خود: اين يرسشنامه سبאآيتمى كه

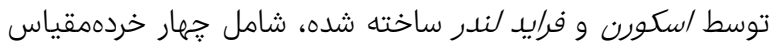

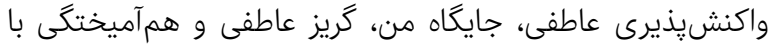

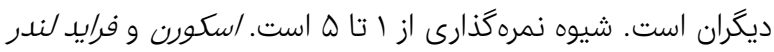

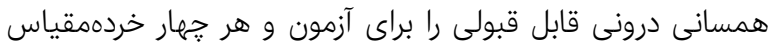

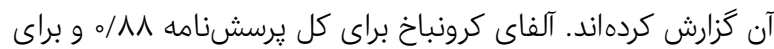

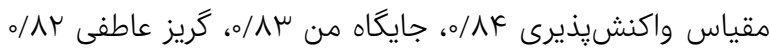

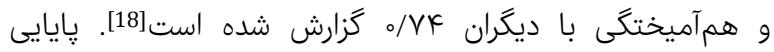
يرسشناهه در اين مطالعه، با استفاده از آلفاى كرونيان

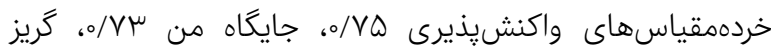

جدول () مقايسه ميانكَين آمارى نمرات متغيرهاى تابآورى، تمايزيافتخى خود و سبك زندگى ارتقادهنده سلامت در جهار گروه مورد مطالعه با استفاده از آزمون تحليل

\begin{tabular}{|c|c|c|c|c|c|c|}
\hline سطح معنىدارى & Fقدار F F F F & گروه فرزندان آزادگان & $\begin{array}{c}\text { كروه فرزندان افراد } \\
\text { عادى }\end{array}$ & $\begin{array}{c}\text { كروه فرزندان جانبازان } \\
\text { غيرشيميايى }\end{array}$ & كروه فرزندان جانبازان & متغيرها \\
\hline$\% \circ \mathrm{V}$ & $K_{0} / \Lambda_{0}$ & $\Lambda \mu / K r \pm I F / V r$ & $q_{0} / V_{0} \pm 19 / Y \mu$ & $\Lambda Q / K_{\circ} \pm 1 \Lambda / \circ r$ & $\Lambda I / 4 \Delta \pm I \mu / \& V$ & تابآورى \\
\hline$\%$ & 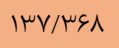 & $|r q / r q \pm| r / q \mu$ & $\left|\omega_{0} / q_{0} \pm \varepsilon / \mu\right|$ & $|\mu k / 4| \pm \mid \psi / 0 \Delta$ & $\|\mu / \mu \bigvee \pm\| F / \Lambda \varepsilon$ & تمايزيافتكى خود \\
\hline$\% 001$ & $1 Q / \Delta q K$ & $\| \varepsilon / \varepsilon \mu_{ \pm} q / V r$ & $1 Y Y / \Delta S \pm 10 / V S$ & $1.9 / \Delta \Lambda \pm \mu_{0} / q \mu$ & 1. $K / 98 \pm T \Delta / T r$ & سبك زندگى ارتقادهنده \\
\hline
\end{tabular}

جايكاه من، گريز عاطفى و همآميختخى و نيز مولفههاى سبك

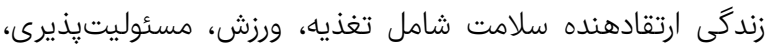

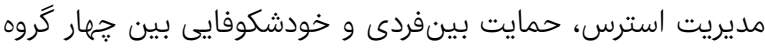
تفاوت معنىدار وجود داشت كه با توجه به بالابودن ميانگين نمرات

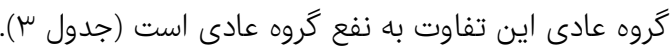

در بررسى دوبهدوى گروهها، بين گروه فرزندان افراد عادى با

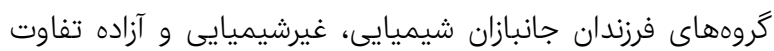

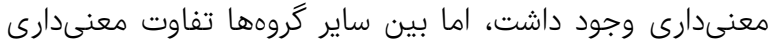

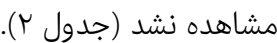

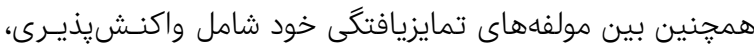


جدول r) مقايسه دوبهدوى گروهها از نظر متغيرهاى يزوهش با استفاده از آزمون تعقيبى توكى

\begin{tabular}{|c|c|c|}
\hline سطح معنىدارى & تفاوت ميانكين & كروهها \\
\hline & & ت ت تابآورى \\
\hline$\circ \% \circ 9$ & $9 / Y \Delta \pm Y / G Y$ & عادى- شيميايى \\
\hline$\% \circ K^{2}$ & $\Delta / \mu_{ \pm} \pm Y / \varphi q$ & عادى- غيرشيميايى \\
\hline$\%$ & $V / r \Lambda \pm I / \mu \mu$ & عادى- آزاده \\
\hline$\circ / \Delta K \mu$ & $-r / ৭ \omega \pm r / द ৭$ & شيميايى- غيرشيميايى \\
\hline$\circ / 9 V Y$ & $-1 / q V \pm F / K F$ & شيميايى- آزاده \\
\hline$\circ / 9 \vee 9$ & $1 / Q \Lambda \pm \kappa / \mu k$ & غيرشيميايى- آزاده \\
\hline & & تمايزيافتكى خود \\
\hline$\circ \% \circ 01$ & 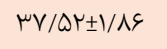 & عادى- شيميايى \\
\hline$\circ \% 001$ & $|\varepsilon / 4 \wedge \pm| / \wedge \varepsilon$ & عادى- غيرشيميايى \\
\hline$\%$ \% r & $11 / \xi \mu_{ \pm} \pm \mu / \%$ & عادى- آزاده \\
\hline $0 / k \mu$ & $-r / \circ \mu \pm 1 / \wedge \varphi$ & شيميايى- غيرشيميايى \\
\hline$\circ / \mu \Delta q$ & $-\mu / \Lambda \omega_{ \pm} r / \mu \kappa$ & شيميايى- آزاده \\
\hline$\circ / F \Delta Q$ & $-\kappa / \Lambda \Delta \pm \psi / \circ \circ$ & غيرشيميايى- آزاده \\
\hline & & سبك زندگى ارتقادهنده سلامت \\
\hline$\circ / 0001$ & $r r / q_{0} \pm \mu / V \mu$ & عادى- شيميايى \\
\hline$\circ \% 001$ & $r_{0} / 9 Y \pm \mu / V \mu$ & عادى- غيرشيميايى \\
\hline$\% \circ \mathrm{V}$ & $10 / 9 \mu_{ \pm} \pm \varepsilon / 0 r$ & عادى- آزاده \\
\hline ॰/৭૬૬ & $-1 / q Y \pm \mu / V \mu$ & شيميايى- غيرشيميايى \\
\hline $0 / 499$ & $-11 / 9 \varepsilon \pm \varepsilon / 0 r$ & شيميايى- آزاده \\
\hline o/KrA & $-10 / 0 r \pm 8 / 0 r$ & غيرشيميايى- آزاده \\
\hline
\end{tabular}

جدول سا) مقايسه ميانكَين آمارى نمرات مولفههاى متغيرهاى تمايزيافتكى و سبك زندگى ارتقادهنده سلامت در جهار گروه مورد مطالعه با استفاده از آزمون آناليز واريانس

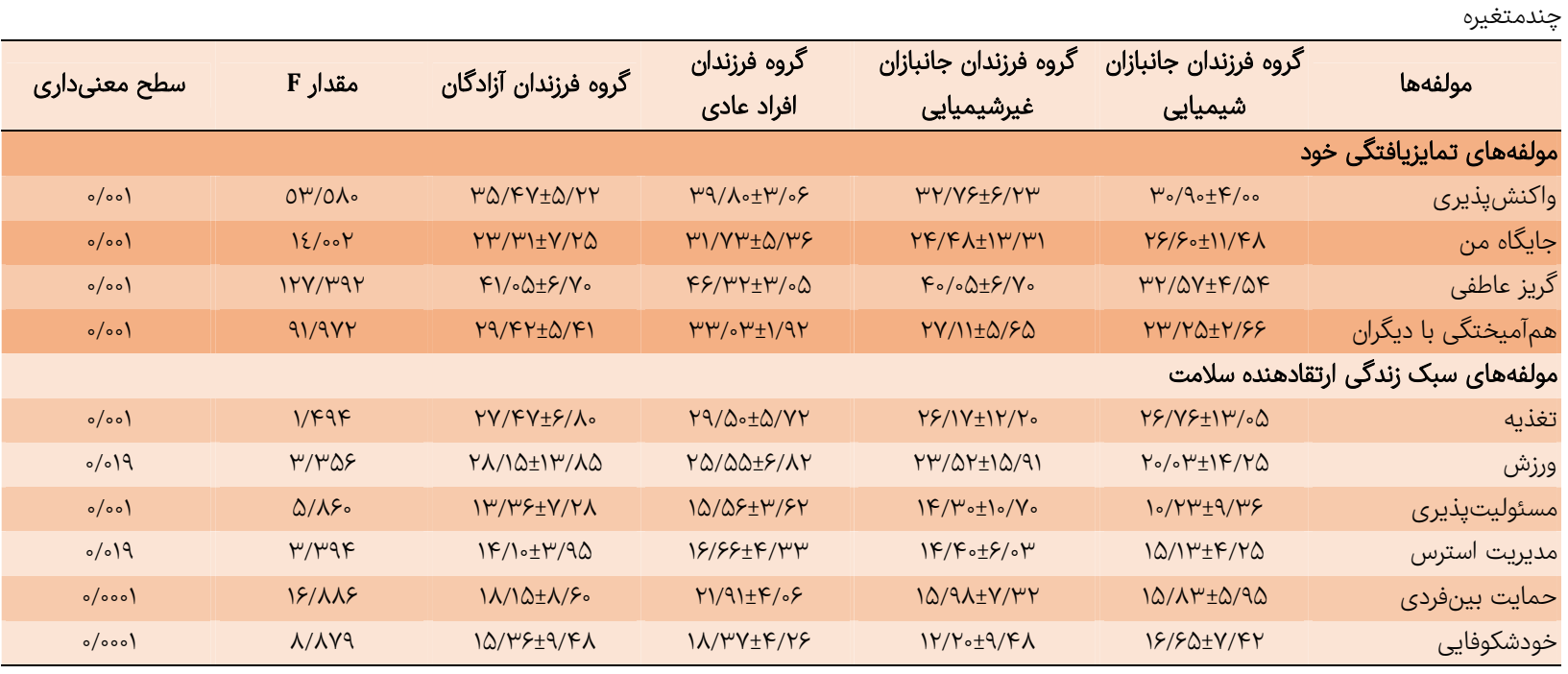

وجود دارد؛ اين به اين معنى است كه ميزان تابآورى در فرزندان

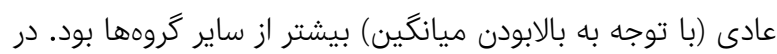

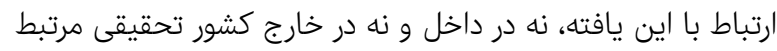

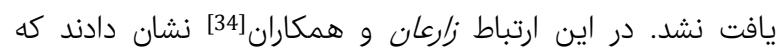

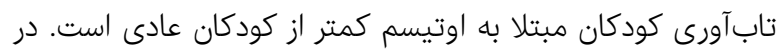

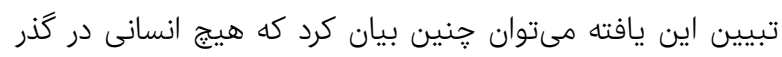

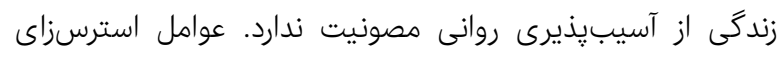

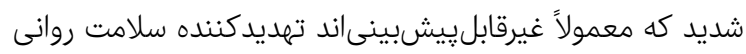

بحث يزوهش حاضر با هدف مقايسه ميزان تابآورى، تمايزيافتكى خود

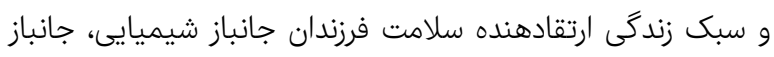

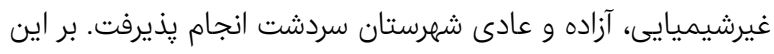

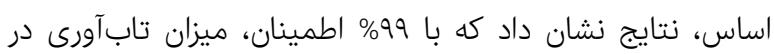

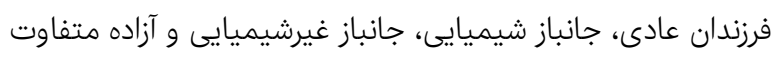

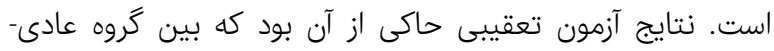

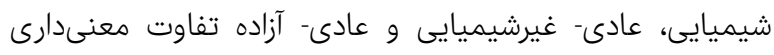


در نهايت نتايج نشان داد كه با 99\% اطمينان ميزان سبك زندكى

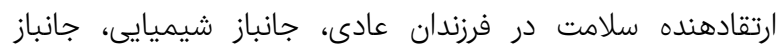

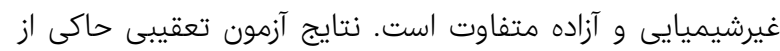

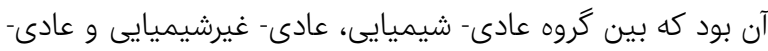

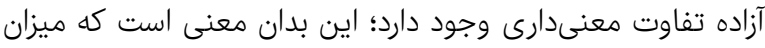

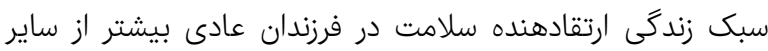

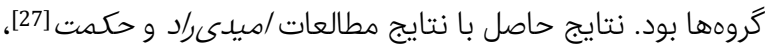

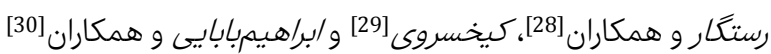

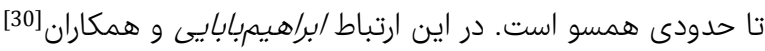

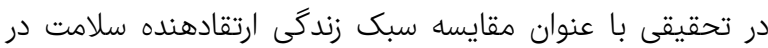

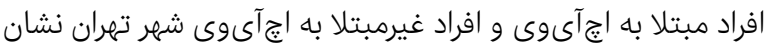

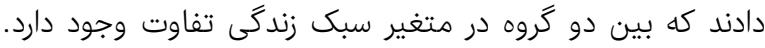

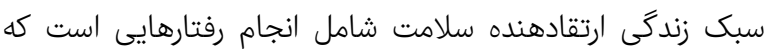

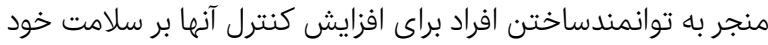

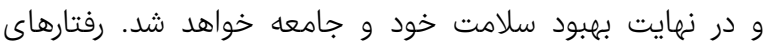
ارتقادهنده سلامت بهعلت داشتن توانايى بالقوه براى بِيشكيرى از

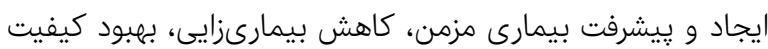

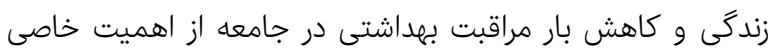

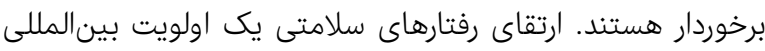

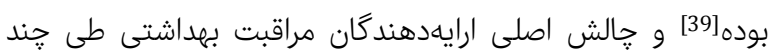

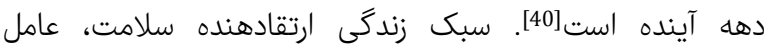

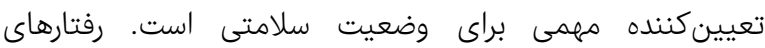
ارتقادهنده سلامت و سبك زندگى سالم، راهبردهاى اصلى براى تسهيل و حفظ سلامت هستند. اين موضوع در اهداف "برنامها بهداشت براى همه" سازمان بهداشت جهانى تاكيد شده است.

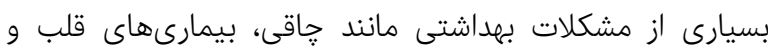

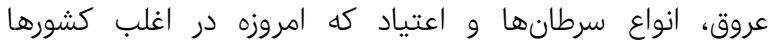

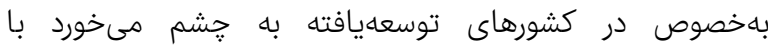

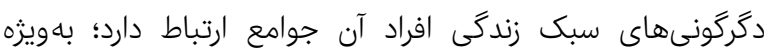

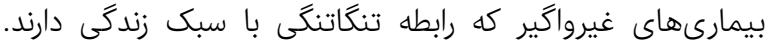

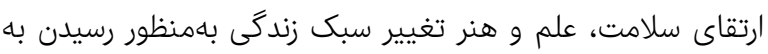

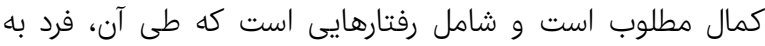
تغذيه مناسب، ورزش منظم، اجتناب از رفتارهاى مخرب و و مواد

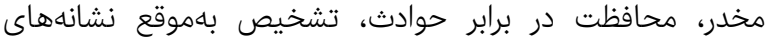

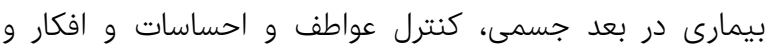

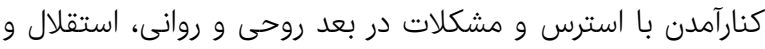
سازكارى و اصلاح روابط بينفردى در بعد اجتماعى مى بيردازد. علت

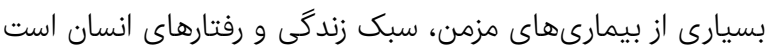

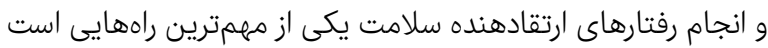

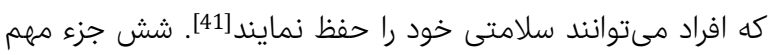

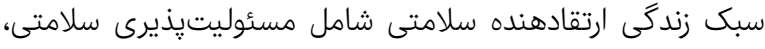

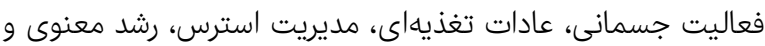

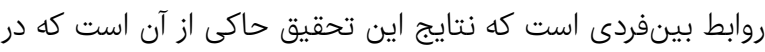

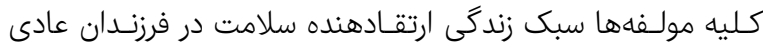

هستند و انسانها در شرايط استرسزا، يكسان واكنش نشان

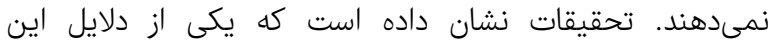

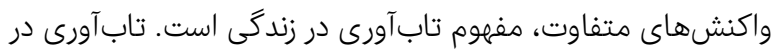

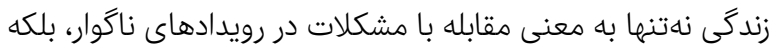

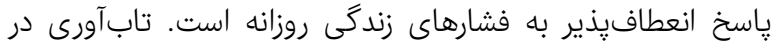

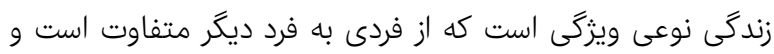

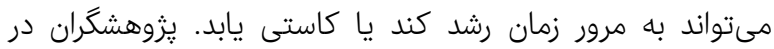

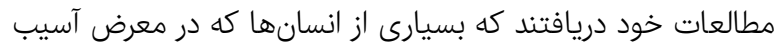

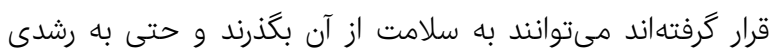

بيش از بيش دست يابند [35].

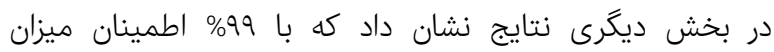

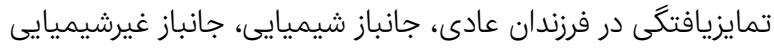

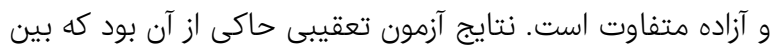

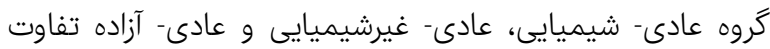

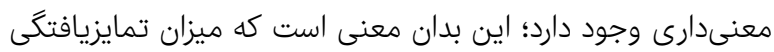

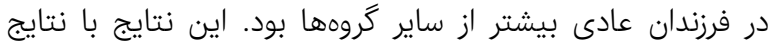

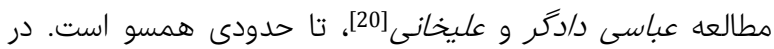

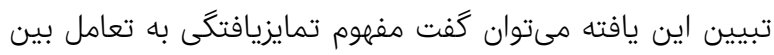

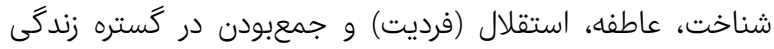

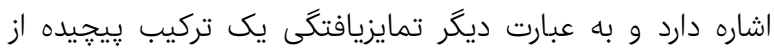

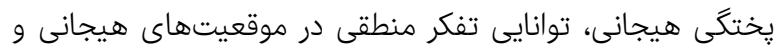

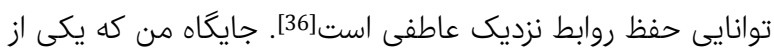
ابعاد تمايزيافتگى است به توانايى شخص در ارئ ارايه تعريف واضحى

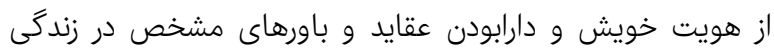

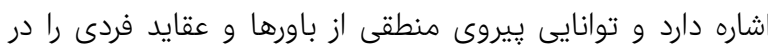

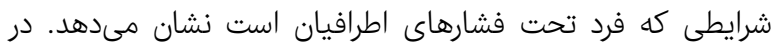

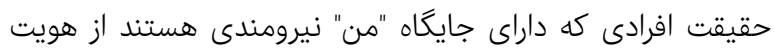

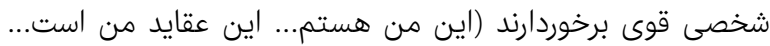

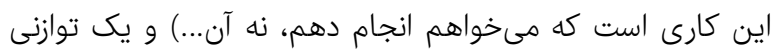

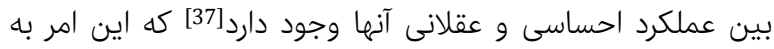
آنها كمك مى كند بر يايه رفتارهايى در قلمرو احساسى و ناخوداكاًاه،

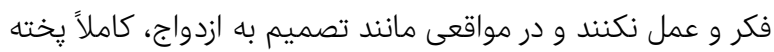

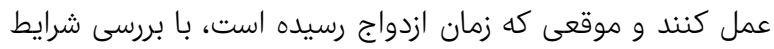

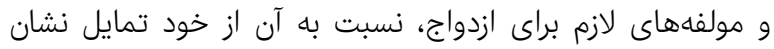

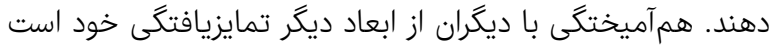

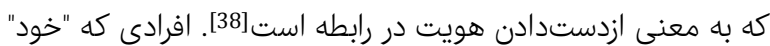

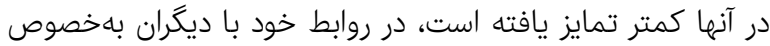

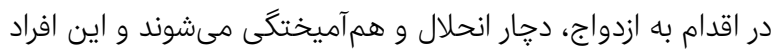

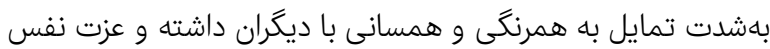

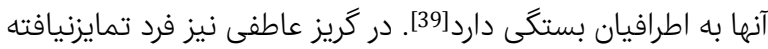

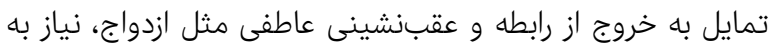

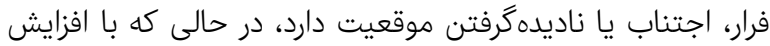

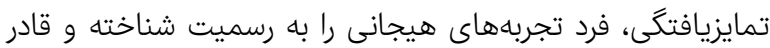

خواهد بود با هيجانات قوىتر روبهرو شود و با آنها كنار بيايد [40]. 
مقايسه ميزان تابآورى، تمايزيافتكى خود و سبك زندكى ارتقادهنده سلامت بين فرزندان جانبازان... IM

3- Keramati H, Moradi AR, Kaveh M. Investigating and comparing the family function and psychological imagery in the children of the martyr family. J Educ Innovat. 2005;4(11):57-75. [Persian].

4- Masten AS. Ordinary majic: resilience processes in development. Am Psychol. 2001;56(3):227-38.

5- Connor KM, Davidson JR. Development of a new resilience scale: the Connor-Davidson Resilience Scale (CD-RISC). Depress Anxiety. 2003;18(2):76-82.

6- Khodabakhshi Koolaei A, Heidari S, Khoshkonesh A, Heidari M. Relationship between spiritual intelligence and resilience to stress and the preference of delivery method among pregnant women. J Obstet Gynecol Infertil. 2013;16(58):8-15. [Persian]

7- Garmezy N. Resilience and vulnerability to adverse developmental outcomes associate with poverty. Am Behav Sci. 1991;34(4):416-30.

8- Martin AJ, Marsh HW. Academic buoyancy: towards an understanding of students' everyday academic resilience. J Sch Psycol. 2008;46(1):53-83.

9- Letzring TD, Block J, Funder DC. Ego-control and egoresiliency: Generalization of self-report scales based on personality descriptions from acquanintances, clinians, and the self. J Res Pers. 2005;39(4):395-422.

10- Moghanloo M, Kolivand Z. Comparison of differentiation of self and cognitive self-control between addicts with a successful withdrawal attempt and drug dependent individuals. J Res Addict. 2018;12(46):101-20. [Persian]

11- Mehri Y, Salari SM, Langroudi MS, Baharamizadeh H. The relationship between differentiation of self and aspects of identity. Proc Soc Behav Sci. 2011;30:733-7. [Persian]

12- Bowen M. Family therapy in clinical practice. New York: Jason Aronson; 1978.

13- Kerr ME, Bowen M. Family evaluation. New York: Norton; 1988.

14- Maser MJ. A construc validiyy of differentiation of self measures and their correlates [Dissertation]. South Orange, New Jersey: Seton Hall University; 2011.

15- Hooper LM, DePuy V. Mediating and moderating effects of differentiation of self on depression symptomatology in a rural community sample. Fam J. 2010;18(4):351-68.

16- Chung H, Gale H. Comparing self-differentiation and psychological well-being between Korean and European American students. Contemp Fam Ther. 2006;28(3):36781.

17- Williamson I, Sandage SJ, Lee RM. How social connectedness affects guilt and shame: Mediation by hope and differentiation of self. Pers Individ Differ. 2007;43(8):2159-70.

18- Skowron EA, Wester SR, Azen R. Differentiation of self mediates college stress and adjustment. J Couns Dev. 2004;82(1):69-78.

19- Johnson P, Buboltz WC. Differentiation of self and psychological reactance. Contemp Fam Ther. 2000;22(1):91-102.

20- Sandage SJ, Jankowski PJ. Forgiveness, spiritual instability, mental health symptoms, and well-being: mediator effects of differentiation of self. Psychol Relig Spiritual. 2010;2(3):168-80.

21- Sepah Mansoor M, Bagheri F. Predicting health promoting lifestyle from health locus of control and attachment style. J Health Psychol. 2017;6(2):131-44. [Persian]
نسبت به سه گروه ديكر (شيميايى، غيرشيميايى و آزاده) بالاتر است. با توجه به يافتههاى حاصل از يزوهش حاضر و اين كه ميزان

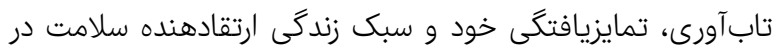

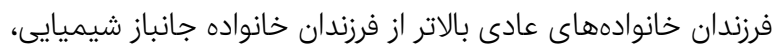

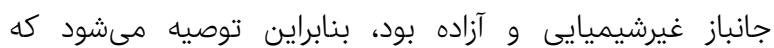

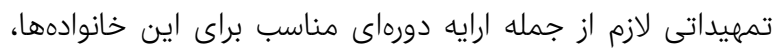

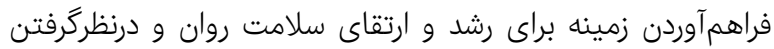

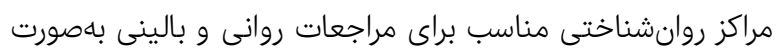
دسترس فراهم آيد. يزوهش حاضر با محدوديتهايى مانند محدوديت نمونه ايليرى

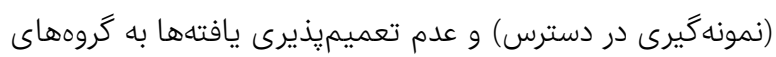

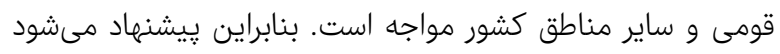
يزوهشى با محدوده جغرافيايى و جامعه آمارى ديكر انجام و نتايج

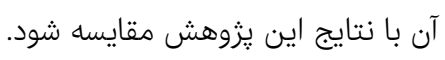

نتيجه گيرى

ميزان تابآورى، تمايزيافتگى خود و سبكى زندگى ارتقادهنده

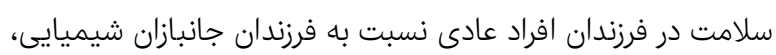
جانبازان غيرشيميايى و آزاده بالاتر است.

تشكر و قدردانى: نويسندكان مراتب تشكر خود را از بنياد شهيد و

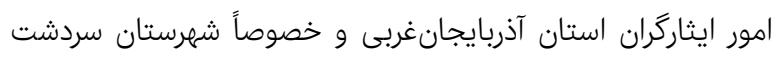

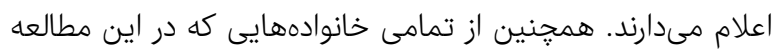
مشاركت نمودند كمال تشكر و قدردانى را داريم.

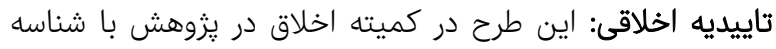
IR.IAU.TABRIZ.REC.1398.010 مورد تصويب قرار كرفت درئ. همجنين قبل از انجام يزوهش رضايت كامل افراد براى شركت در

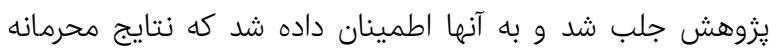
باقى مىماند و براى كاهش نكرانىهاى احتمالى به آزمونش آشوندگًان

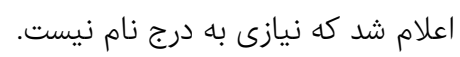

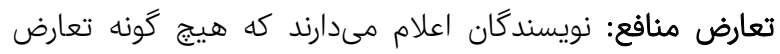
منافعى در اين تحقيق وجود ندارد.

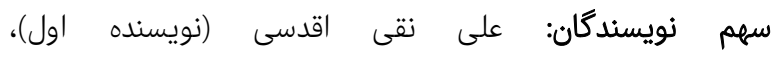
روششناس/يزوهشگر كمكى/تحليلكر آمارى (0\%)؛ بيانه

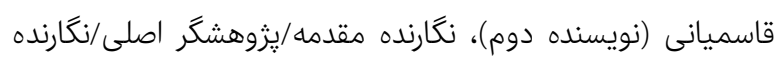
بحث (\%00) منابع مالى: تزروهش حاضر از هشتيبانى مالى هيج موسسه و سازمانى برخوردار نبوده است.

\section{منابع}

1- Bahrainian A, Borhani H. Mental health in group of war veterans and their spouses in Qom. Res Med. 2003;27(4):305-12. [Persian]

2- Shoarinejad AA. Teacher and family career needs. Q J Educ. 1930;116:37-40 [Persian]. 
Opportunities and Challenges in the fields of Culture, Economics and Politics; 2009 Mar 4; University of Mazandaran, Babolsar, Iran. [Persian]

32- Mojahed A, Kalantari M, Molavi H, Taher Neshatdost $\mathrm{H}$, Shakiba M. comparative study of the mental health of war injured and martyrs' spouses in Zahedan. Horizon Med Sci. 2011;17(3):43-50. [Persian]

33- Samani S, Jokar B, Sahragard, N. Resilience, mental health and life satisfaction. J Psychiatry Clin Psychol Iran. 2007;13(3):290-5. [Persian]

34- Zarean Z, Nazari F, Hajir S, Alvandi P. Comparison of resiliency in parents of children with autism and the effectiveness of parental education in improving resilience. National Congresses for Children with Special Needs; 2018 Apr 25; Farhangiyan University, Isfahan, Iran. Tehran: Civilica; 2018. [Persian]

35- Khalatbari J, Bahari S. The relationship between resilience and life satisfaction. J Educ Psychol. 2010;1(2):83-94. [Persian]

36- Drake JR. Differention of self inventoty short form: creation and initial evidence of construct validity [Dissertation]. Kansas City: University of Missuri Kansas City; 2011.

37- Yousefi N. Psychometric measures of family scale, selfdifferentiation. J Fam Couns Psychother. 2011;1(1):1938. [Persian]

38- Goldenberg H, Goldenberg I. Family therapy: an overview. $8^{\text {th }}$ Edition. United States: Brooks/Cole; 2012.

39- Myers RE. Promoting healthy behaviors: how do we get the message across? Int J Nurs Stud. 2010;47(4):50012.

40- Barnes D, Almasy N. Refugees' perceptions of healthy behaviors. J Immigr Health. 2005;7(3):185-93.

41- Mohammadalizadeh Charandabi S, Mirghafourvand M, Tavananejad N, Karkhaneh M. Health promoting lifestyles and self-efficacy in adolescent boys. J Mazandaran Univ Med Sci. 2014;23(109):152-62. [Persian]
22- Mohammadi Zeidi I, Pakpour Hajiagha A, Mohammadi Zeidi B. Reliability and validity of Persian version of the health-promoting lifestyle profile. J Mazandaran Univ Med Sci. 2012:21(1):102-13. [Persian]

23- La'li M, Abedi A, Kajbaf MB. Construction and validation of the lifestyle questionnaire (LSQ). Psychol Res. 2011;15(1):64-80. [Persian]

24- Baker D. Health promotion in nursing practice. Fam Community Health; 2007;30(1):85-6.

25- Chaney D. Cosmopolitan art and cultural citizenship. Theory Cult Soc. 2002;19(1-2):157-74.

26- Lock CA, Lecouturier J, Mason JM, Dickinson HO. Lifestyle interventions to prevent osteoporotic fractures: a systematic review. Osteoporos Int. 2006;17(1):20-8.

27- Omidy Rad S, Hekmat HR. Comparison of health promotion and happiness promoting style in Adolescents without a guardian and Single-guarded and normal Adolescents. In: Proceedings of the World Conference on Psychology and Educational Sciences of the Social Sciences Law at the beginning of the third millennium; 2016 May 19; Green Industry Market Idea Company Research, Shiraz, Iran. Tehran: Civilica; 2017. [Persian] 28- Rastgar M, Zendehtalab HR, Yavari M, Mazloum SR. Health promoting lifestyle and its related factors in health volunteers in Mashhad. J Torbat Heydariyeh Univ Med Sci. 2015;3(3):48-55. [Persian]

29- Kaykhosravi N. Investigating the relationship between differentiation and dependence with identity styles in students at Behshahr Islamic Azad University [Dissertation]. Behshahr: Behshahr Islamic Azad University; 2017. [Persian].

30- Ebrahim Babaei F, Habibi M, Ghodrati S. Comparison of health promoting lifestyle in HIV-positive and HIVnegative individuals in Tehran. J Educ Community Health. 2017;4(3):38-43. [Persian]

31- Javidi Kalate Jafarabadi T. Social status of Martyrs' Spouses (Neyshabur City). In: Proceedings of the National Conference on Self-sacrifice and Martyrdom, 